\title{
Editorial
}

\section{Rebooting EU employment law}

About two months ago it was all over the news in various countries: a fitness app used by military personnel on an international mission may very well have revealed the whereabouts of a military base which was supposed to be secret. The app concerned put online the route taken by the soldiers during their daily run. This news item shows that we are still not fully used to modern technology, including its impact on privacy.

The same can be seen when it comes to EU employment law. We are in the midst of figuring out the impact of technology on the employment relationship, as this edition shows. May a racist 'liking' on Facebook justify dismissal for serious misconduct, or should this fall within the ambit of the permissible use of freedom of speech? And what about the employer using surveillance software to monitor the employee: is that advanced research tool allowed or is it an inexcusable violation of the privacy rights of the employee? And what to think about Uber platform workers? Are they self-employed or not? These relatively new questions will undoubtedly influence and possibly dominate case law in the years to come.
Having said that, questions on more classical EU employment law topics remain relevant as well, such as discrimination and transfers of undertakings. The burden of proof in discrimination cases is still an issue in the United Kingdom, whilst Germany addresses the question of when the limitation period starts in such cases. Whether a change of service provider triggers the transfer of an undertaking is scrutinised in Italy, whilst the Hungarian Court looks into the scope of the dismissal protection following a transfer.

But we also have, in this issue, a review of the developments in EU employment law during 2017, mostly written by members of our Academic Board. They cover ten topics, including private international law, various forms of discrimination, transfers of undertakings, dismissals (both collective and in relation to privacy) and free movement. In other words: there is something for everyone. Enjoy!

Zef Even, editor 